\title{
Sistema nacional electoral. El gran reto
}

\section{Leticia Catalina Soto Acosta*}

\section{Sumario:}

I. Introducción

II. Sistema nacional electoral

III. Facultades del Instituto Nacional Electoral

IV. Facultades especiales del Instituto Nacional Electoral

V. Facultades de los organismos públicos locales electorales

VI. Conclusiones

VII. Fuentes consultadas

* Consejera presidenta del Instituto Electoral del Estado de Zacatecas. Doctora en Derecho por el Instituto Internacional del Derecho y del Estado de la Universidad Autónoma de Zacatecas. 


\section{Introducción}

Con la reforma a la Constitución Política de los Estados Unidos Mexicanos (CPEUM), en materia político-electoral, que se publicó en el Diario Oficial de la Federación el 10 de febrero de 2014, se modificó de manera sustantiva el sistema electoral mexicano, con una distribución de competencias entre el Instituto Nacional Electoral (INE) y los organismos públicos locales electorales y del Distrito Federal, lo que genera nuevas formas y reglas para operar la función electoral en el país.

Resulta oportuno señalar, que el punto de partida de discusión sobre el sistema electoral mexicano, se dio en el gran acuerdo político denominado "Pacto por México", que se firmó el 2 de diciembre de 2012 entre el gobierno de la República y las principales fuerzas políticas del país; en éste, se propuso crear una autoridad electoral de carácter nacional encargada de la organización de las elecciones en el país, a través de una legislación única.

Los argumentos planteados por diversos partidos políticos en torno a la redefinición de las competencias y la integración de los organismos públicos locales electorales, partieron de las premisas siguientes: 1) la intromisión de los gobernadores de los estados en las autoridades electorales locales, y 2) que la organización de los comicios estatales por las autoridades locales acrecentaban el costo de las elecciones. Sin embargo, ninguna de estas premisas fue demostrada de manera objetiva.

Conviene precisar que antes de la aprobación de la reforma constitucional, el sistema electoral mexicano estaba configurado como un modelo federal, en el que convivían la autoridad encargada de organizar los comicios para la integración del Ejecutivo Federal y del Congreso de la Unión así como las treinta y dos autoridades de las entidades federativas, encargadas de las elecciones del Ejecutivo local, los congresos y los ayuntamientos.

Ahora, transitamos al sistema dual que busca generar una rectoría y homologación en los procesos electorales en el país y en el que el INE y los organismos públicos locales electorales cuentan con facultades originarias, especiales, delegadas y concurrentes.

El primer reto que enfrentará el nuevo sistema nacional electoral, serán las elecciones de 2015, en que ocurrirá la elección federal de diputados y las diecisiete elecciones que se llevarán a cabo en diversas entidades 
federativas, ${ }^{1}$ en las que se renovarán 9 gubernaturas, 640 diputaciones $\mathrm{y}$ 908 ayuntamientos.

Esta reforma ha sido muy debatida y cuestionada pero la realidad es que se trata de un mandato constitucional de cumplimiento obligatorio. Por lo que este artículo tiene como finalidad realizar un análisis de esta nueva distribución de competencias para el desarrollo de la función electoral en el país.

\section{Sistema nacional electoral}

De acuerdo con Dieter Nohlen el término "sistema electoral" se refiere "al principio de representación que subyace al procedimiento técnico de elección, y al procedimiento mismo por medio del cual los electores expresan su voluntad política en votos que a su vez se convierten en escaños o poder público". ${ }^{2}$

Por función electoral debemos entender la especificación normativa de una actividad primordial del Estado referida a la organización, realización y calificación de las elecciones como mecanismo de integración de los órganos representativos del poder público. Se trata de una función que se enmarca dentro de las funciones estatales, en la medida en la que es llevada a cabo por determinadas entidades administrativas y jurisdiccionales especializadas que son órganos del Estado y que, en cuanto tales, desarrollan un tipo específico de tareas estatales que son las de realizar los proceso electorales de los que emana la representación democrática. ${ }^{3}$

Los sistemas electorales son producto de la evolución histórica, por lo que sus efectos políticos han dependido siempre de la estructura social, de las instituciones existentes y del comportamiento político de los electores, en consecuencia, de las condiciones prevalecientes en cada país. ${ }^{4}$

A lo largo de 30 años, el sistema electoral mexicano ha cambiado debido a diversas reformas, que obedecen a las transformaciones políticas del país, las más importantes han sido:

1 Baja California Sur, Campeche, Colima, Chiapas, Distrito Federal, Guanajuato, Guerrero, Jalisco, Estado de México, Michoacán, Morelos, Nuevo León, Querétaro, San Luis Potosí, Sonora, Tabasco y Yucatán.

2 Nohlen, Dieter, Los sistemas electorales en América Latina y el debate sobre la reforma electoral, México, UNAM, 1993, p. 11.

3 Astudillo, César y Córdova, Lorenzo, Los árbitros de las elecciones estatales. Una radiografía de su arquitectura institucional, México, UNAM, 2010, p. 1.

4 Fuente, Alejandro de la, El sistema electoral en México, http://www.letrasjuridicas. com/Volumenes/14/delafuente14.pdf, p. 2. 
- La reforma de 1977 permitió la participación en el sistema político a las fuerzas de izquierda, que hasta entonces habían tenido una actuación marginal y no alcanzaban la representación formal. El objetivo de esa reforma residió en que las minorías contarán con presencia en los órganos de representación política.

- En 1986, se promulgó el Código Federal Electoral; se derogó el registro condicionado de partidos y el número de diputaciones federales de representación proporcional llegó a 200.

- En 1990 se expidió el Código Federal de Instituciones y Procedimientos Electorales y se creó el Instituto Federal Electoral, órgano independiente del gobierno para organizar las elecciones federales, que sustituyó a la Comisión Federal Electoral que dependía directamente de la Secretaría de Gobernación.

- En 1993 y 1994 hubo dos reformas cuyos principales tópicos fueron la incorporación de los consejeros ciudadanos en el Consejo General del Instituto Federal Electoral, que sustituyeron a los consejeros magistrados; el nuevo financiamiento para los partidos, las nuevas reglas para reportar sus egresos, así como los gastos anuales y de campaña.

- La reforma de 1996 otorgó plena autonomía a los órganos electorales, terminó con la participación y control gubernamental en el proceso de organización de las elecciones federales.

Astudillo y Córdova identifican el año de 1993 como el punto de inflexión en la forma de ejercicio del poder público, pues en ese año se introduce a nuestro orden jurídico la existencia de organismos constitucionalmente autónomos, cuya principal característica es la distancia política, administrativa y financiera de los tres poderes clásicos del Estado, el Ejecutivo, el Legislativo y el Judicial. Nuestro orden constitucional propuso la existencia de órganos técnicos especializados, blindados a las influencias de los otros poderes, para que ejercieran facultades en temas centrales de la vida nacional. Así, en 1993 se confiere la autonomía al Banco de México, en 1996 al Instituto Federal Electoral, en 1999 a la Comisión Nacional de Derechos Humanos, al Instituto Nacional de Estadística, Geografía e Informática en el $2006,{ }^{5}$ y en la reciente reforma a la Constitución se ha otorgado la autonomía al Instituto Federal de Acceso a la Información, al Consejo Nacional de Evaluación de la Política de Desarrollo Social y a la Fiscalía General de la República. ${ }^{6}$

Astudillo, César y Córdova, Lorenzo, op. cit., p. 38.

${ }^{6}$ Decreto publicado en el Diario Oficial de la Federación, 10 de febrero de 2014. 
Tras la autonomía constitucional otorgada al Instituto Federal Electoral, y en cumplimiento a las bases establecidas en el artículo 116 fracción IV, de la CPEUM, las entidades federativas armonizaron el régimen jurídico de las instancias electorales y dotaron de autonomía, personalidad jurídica y patrimonio propio a los órganos administrativos.

La reforma de 2007 anunciaba la intención de centralizar la función electoral en una sola autoridad nacional. Apareció la posibilidad de que el Instituto Federal Electoral conviniera con las entidades federativas la organización de las elecciones locales. Generó un nuevo régimen de distribución de facultades, al asumir como autoridad única la administración de los tiempos en radio y televisión y la superación del secreto bancario y fiscal para los trabajos de fiscalización relativos a los partidos políticos.

Estas reformas dan cuenta de que el sistema electoral mexicano se ha planteado, desde hace ya más de dos décadas, la necesidad de la existencia de órganos técnicos, especializados, blindados, que tengan a su cargo una función especial del Estado, y que desde hace más de un lustro, se plantea la centralización de las elecciones en el país.

El Instituto Internacional para la Democracia y la Asistencia Electoral (IDEA Internacional) ha sostenido que el sistema de gobierno imperante en un país determina en buena medida el nivel de concentración o delegación de atribuciones en su organismo electoral. En el orden jurídico se puede distinguir entre las atribuciones y funciones que se les confieren a los organismos electorales a nivel nacional o central, y aquellas que se les confieren a los organismos electorales a nivel regional o subnacional.

Respecto a los modelos o tipos de organismos electorales, el IDEA señala que hay tres grandes: modelo independiente; modelo gubernamental y modelo mixto. ${ }^{7}$

Los organismos electorales de modelo mixto, son los que tienen una estructura dual, con un componente encargado de funciones de dirección, vigilancia o supervisión, que es independiente de la rama ejecutiva del gobierno y un componente ejecutivo u operativo ubicado dentro de un ministerio o gobierno local.

Los organismos electorales de modelo gubernamental o mixto, pueden apoyarse en las autoridades locales para conducir todas o algunas de

7 Dictamen de las Comisiones Unidas de Puntos Constitucionales; de Gobernación; de Reforma del Estado, y de Estudios Legislativos Segunda, de la Cámara de Senadores, en relación con las iniciativas con Proyecto de Decreto por el que se reforman y adicionan diversos artículos de la Constitución Política de los Estados Unidos Mexicanos en materia política-electoral, del 2 de diciembre de 2013, pp. 121-123. 
las actividades electorales. Sin embargo, este esquema puede dificultar que se mantengan algunos patrones de consistencia, servicio, calidad y, en última instancia, de libertad y justicia en las elecciones.

En México, como hemos señalado, existen organismos electorales a nivel nacional y en cada uno de los estados.

\section{1. ¿Hacia dónde hemos transitado?}

Antes de la reforma, el sistema electoral mexicano estaba configurado como un sistema federal descentralizado, que se integraba por un subsistema nacional y por treinta y dos subsistemas en las entidades federativas.

Los subsistemas estatales reproducían en su ámbito las pautas dominantes en el subsistema federal, y de este modo los procesos electorales eran responsabilidad directa de cuerpos de funcionarios profesionales, de los representantes de los partidos sin derecho a voto y, aunque no en todos los casos, por representantes de los poderes legislativos. El órgano máximo de dirección estaba integrado por las consejeras y los consejeros electorales designados por las legislaturas de los estados y el Congreso de la Unión. ${ }^{8}$

Las bases de colaboración, durante los comicios locales en materia de cartografía electoral; padrón de electores y listado nominal, se estipulaban en convenios con el otrora IFE y los órganos electorales de las entidades federativas.

El mosaico de realidades políticas y sociales, así como la libertad configurativa de las Legislatura Estatales, generó un régimen jurídico diverso. Lo que trajo consigo un diseño institucional heterogéneo.

A partir de la reforma constitucional de febrero de 2014 y de la expedición de las primeras leyes generales (Ley General de Instituciones y Procesos Electorales; Ley General de Partidos Políticos y Ley General de Delitos Electorales), ahora existe un sistema nacional electoral, un modelo dual, que tiene un órgano constitucional autónomo (INE) encargado principalmente de organizar las elecciones y otro de carácter jurisdiccional. Este modelo dual se replica en cada una de las entidades federativas. En el sistema nacional electoral, se distribuyen competencias entre el INE y los organismos públicos locales electorales, y de esta forma, existen fa-

8 Ensayo Es necesario convertir el Instituto Federal Electoral en autoridad nacional electoral, México, Cámara de Diputados, 2013, p. 2, en www.diputados.gob.mx/documentos/ consejeros_2013/ensayo/04.pdf. 
cultades originarias, especiales, delegadas y concurrentes, para operar la función electoral en el país regulada por lineamientos específicos en las principales materias normados por leyes generales. ${ }^{9}$

Entre los antecedentes inmediatos más destacados de este viraje en la organización electoral, se pueden señalar:

\section{A. El "Pacto por México"}

En su apartado núm. 5.3 se estableció, entre otras cosas, lo siguiente:

\subsection{Partidos Políticos y Elecciones.}

Se impulsará una Reforma Electoral que atienda los siguientes temas (Compromiso 90):...

Crear una autoridad electoral de carácter nacional y una legislación única, que se encargue tanto de las elecciones federales, como de las estatales y municipales...

Este compromiso se basó en dos premisas: 1) la intromisión de los gobernadores de los estados en las autoridades electorales locales, y 2) la organización de los comicios estatales por las autoridades locales acrecentaban el costo de las elecciones.

Respecto a la primer premisa, conviene precisar que existe alternancia política en las entidades federativa, lo que es reflejo de elecciones libres y auténticas, y existen gobiernos locales de muy diversa integración.

La autonomía de los órganos electorales de las entidades federativas es corroborada con las resoluciones que se emiten con motivo de las impugnaciones en contra de sus actos, pues son confirmadas aproximadamente el $84 \%$ de sus decisiones por parte de las salas del Tribunal Electoral del Poder Judicial de la Federación.

En cuanto a la segunda premisa, relativa al costo de las elecciones, se puede advertir que el presupuesto que se asignó al entonces Instituto Federal Electoral para 2013 fue superior al de las treinta y dos autoridades electorales de las entidades federativas (se incluye el presupuesto para

9 De orden público y de observancia general en el territorio nacional y para los ciudadanos que ejerzan su derecho al sufragio en territorio extranjero; que tienen por objeto distribuir competencias entre la federación y las entidades federativas así como la relación entre el INE y los organismos públicos electorales locales. 
la organización de 14 procesos electorales estatales), como se muestra a continuación: ${ }^{10}$

\begin{tabular}{|c|c|c|}
\hline Presupuesto IFE & $\begin{array}{c}\text { Presupuesto órganos electorales } \\
\text { de las entidades federativas }\end{array}$ & Diferencia \\
\hline$\$ 7303782924.07$ & $\$ 4747035935.74$ & $\$ 2556746988.33$ \\
\hline
\end{tabular}

* No considera el financiamiento a los partidos políticos, ni la organización de algún proceso electoral federal.

** No considera el financiamiento a los partidos políticos, si incluye el presupuesto para organizar catorce procesos electorales estatales.

En este sentido, las elecciones ${ }^{11}$ que realizaron los organismos electorales de las entidades federativas en 2013 con el presupuesto asignado, fueron menos costosas que las elecciones federales, ya que el número de cargos de elección popular para los que se organizan procesos electorales es mayor a nivel local que a nivel federal.

Por tanto, la idea inicial era la creación de una autoridad electoral de carácter nacional que se encargara tanto de las elecciones federales como de las estatales y municipales, en suma desaparecer a los órganos electorales de las entidades federativas de los estados.

\section{B. Reforma constitucional en materia político electoral}

En la Cámara de Senadores se presentaron 56 iniciativas de reformas o adiciones a la Constitución Política de los Estados Unidos Mexicanos en materia político-electoral.

Es oportuno traer a cuenta lo que en la exposición de motivos del Decreto de reforma constitucional, en materia político-electoral, se plasmó:

Podemos mencionar que el fortalecimiento de la autoridad nacional electoral garantizará la continuidad y fortaleza del Instituto Nacional Electoral; se retirarán las funciones más controvertidas a los órganos locales que han puesto en duda su imparcialidad; se garantizarían las condiciones de legalidad, certidumbre, equidad y transparencia en los proceso locales; se fortalecen las normas preventivas de la intromisión de otros Poderes en las decisiones y ac-

10 Fuente: decretos de presupuestos de cada estado y el Distrito Federal.

11 Se llevaron a cabo las elecciones siguientes: 1 de gobernador, 442 de diputados y 1348 de ayuntamientos. Fuente: Calendario Electoral 2013, Tribunal Electoral del Poder Judicial de la Federación. 
tuar de los órganos locales y, lo más importante, se reforman y fortalecen las autoridades locales, con el propósito de hacer que los procesos electorales en todo el territorio nacional sean homogéneos, se observen los principios antes citados y se homologuen las calidades de los procesos electorales federal y de las entidades federativas.

En ese tenor de ideas, las Comisiones Unidas al hacer un análisis profundo de las ventajas y desventajas de la creación de un órgano nacional, concluimos que el actuar de los órganos electorales locales puede reforzarse con la intervención del Instituto Nacional Electoral en algunas atribuciones, esto con el propósito de dotar a estos organismos de los principios que deben regir en todo proceso electoral.

Las Comisiones Dictaminadoras también consideramos que para cumplir con el propósito fundamental de imparcialidad, transparencia, independencia, integridad, eficiencia y efectividad, vocación de servicio y profesionalismo en los órganos electorales locales, no es pertinente su desaparición, sino establecer en la Constitución Política de los Estados Unidos Mexicanos, la homologación de algunos aspectos para el cumplimiento de este fin, como son: el procedimiento de nombramiento de los consejeros electorales, su duración y el sistema de garantías para su cabal desempeño.

Así, estas Comisiones Dictaminadoras consideramos necesario realizar algunos ajustes al texto propuesto en las diversas iniciativas materia de este análisis, con el único objeto de colmar los propósitos que se persiguen y contar con una autoridad electoral fortalecida, sin desaparecer los órganos electorales locales, observando los principios rectores de legalidad, certeza, transparencia, honradez y profesionalismo.

De esta forma, la decisión del Poder Constituyente Permanente fue no desaparecer a los órganos electorales de las entidades federativas y "reforzar" su actuación a través de la intervención del INE en algunas atribuciones.

Para armonizar el sistema, se estableció en el artículo segundo transitorio del Decreto de reforma en materia político-electoral a la CPEUM, que el Congreso de la Unión debería expedir las leyes generales de Instituciones y Procedimientos Electorales; de Partidos Políticos y de Delitos Electorales, las que fueron publicadas en el Diario Oficial de la Federación el 23 de mayo de 2014.

Es importante señalar que aún queda pendiente la expedición de la legislación reglamentaria del artículo 134 de la Constitución Política de los Estados Unidos Mexicanos, relativa a la propaganda gubernamental 
y que recordemos es una obligación del Congreso de la Unión desde la reforma de 2007 y que a la fecha no se ha concretizado.

En la exposición de motivos del Decreto por el que se aprobó la expedición de la Ley General de Instituciones y Procedimientos Electorales (LGIPE), se estableció:

... la reforma política-electoral representa avances importantes que pretenden abonar a la consolidación del Estado constitucional y democrático de derecho.

Esta reforma, es el comienzo de la transformación del sistema político mexicano hacia uno más moderno, más acorde a las exigencias sociales y más cercano a modelos internacionales que han demostrado éxito para avanzar a un mejor estadio democrático.

Con ella se fortalece el sistema electoral, transformando al Instituto Federal Electoral en un Instituto Nacional Electoral, con mayores facultades, que ejercerá en toda la República, retomando algunas de las competencias actualmente designadas a los organismos locales.

Permanecen los 32 organismos electorales de las entidades federativas, pero se acotan sus atribuciones y se vinculan de manera directa al nuevo Instituto.

En consecuencia, con el devenir de la reforma electoral emerge el sistema nacional electoral, que finalmente estableció una autoridad rectora de la función electoral, pues en diversas materias tendrá la facultad de emitir reglamentos, lineamientos y criterios, que homologarán la administración de los procesos electorales; además, asume algunas de las facultades que antes se desarrollaban por el órgano electoral local.

El sistema nacional electoral se integra por: el Instituto Nacional Electoral y el Tribunal Electoral del Poder Judicial de la Federación; a nivel local, treinta y dos organismos públicos locales electorales y el mismo número de tribunales electorales locales, que ahora son independientes de los poderes judiciales de las entidades federativas.

El marco Jurídico se constituye por: la Constitución Política de los Estados Unidos Mexicanos, los tratados internacionales, la Ley General de Instituciones y Procedimientos Electorales, la Ley General de Partidos Políticos, la Ley General de Medios de Impugnación en Materia Electoral, la Ley General en materia de Delitos Electorales, la Ley Federal de Responsabilidades Administrativas de los Servidores Públicos, así como treinta y un Constituciones Políticas de los Estados, el Estatuto de Gobierno del Distrito Federal, y treinta y dos legislaciones electorales locales. 
En el sistema nacional electoral, se deberá atender al principio de distribución de competencias entre el Instituto Nacional Electoral y los organismos públicos locales electorales. Las elecciones de 2015 serán un escenario para implementar el nuevo modelo y en éstas, seguramente, el INE definirá los reglamentos, lineamientos y criterios para el ejercicio coordinado de la función electoral; los que serán sometidos a las cadenas impugnativas y generarán un sistema normativo robusto que permitirá una transición adecuada.

En el ámbito del diseño institucional, corresponderá ahora al Consejo General del INE la designación de las consejeras y consejeros electorales en las entidades federativas. Se han aprobado ya los Lineamientos del Instituto Nacional Electoral para la Designación de Consejeros Presidentes y Consejeros Electorales de los Organismos Públicos Locales. ${ }^{12} \mathrm{Se}$ tratará pues de una designación que se realizará en el centro, sin la participación directa de los operadores locales; esta situación resulta contraria a lo recomendado por el Manual de IDEA Internacional sobre la Justicia Electoral, que recomienda que tanto en la integración de los órganos administrativos electorales (OAE) como en el órgano de resolución de conflictos electorales (ORCE) se debe buscar el consenso de los partidos y fuerzas políticas para definir su estructura o integración, pues "dicho consenso no solo contribuye a la legitimidad y credibilidad electoral sino que la confiabilidad en el mismo por parte de los votantes se traduce en mayor participación". ${ }^{13}$

El gran reto será lograr la rectoría y mayor calidad de la función electoral, esto es lo que realmente debe importar si lo que se busca es el fortalecimiento del sistema electoral mexicano.

\section{Facultades del Instituto Nacional Electoral}

El artículo 41, Base V, Apartados B y C, incisos $a, b$ y $c$ de la CPEUM, se convierte en el artículo distribuidor de facultades, pues establece las que tendrá el INE en los procesos electorales federales y locales y las facultades que tendrá en los procesos electorales locales.

12 Acuerdo INE/CG44/2014 del Consejo General del INE.

13 IDEA Internacional, Justicia Electoral: El manual de IDEA Internacional, 2013, p. 29. 


\section{Procesos electorales federales y locales}

- La capacitación electoral.

- La geografía electoral, así como el diseño y determinación de los distritos electorales y división del territorio en secciones electorales.

- El padrón y la lista de electores.

- La ubicación de las casillas y la designación de los funcionarios de sus mesas directivas.

- Las reglas, lineamientos, criterios y formatos en materia de resultados preliminares; encuestas o sondeos de opinión; observación electoral; conteos rápidos; impresión de documentos y producción de materiales electorales.

- La fiscalización de los ingresos y egresos de los partidos políticos y candidatos.

\section{Procesos electorales federales}

- Los derechos y el acceso a las prerrogativas de los candidatos y partidos políticos.

- La preparación de la jornada electoral.

- La impresión de documentos y la producción de materiales electorales.

- Los escrutinios y cómputos.

- La declaración de validez y el otorgamiento de constancias en las elecciones de diputados y senadores.

- El cómputo de la elección de presidente de los Estados Unidos Mexicanos en cada uno de los distritos electorales uninominales.

Según lo previsto en el artículo transitorio décimo segundo de la Ley General de Instituciones y Procedimientos Electorales, las funciones correspondientes a la capacitación electoral, así como la ubicación de las casillas y la designación de funcionarios de la mesa directiva, en los procesos electorales locales, se mantendrán delegadas a los organismos públicos locales electorales, hasta en tanto no sean reasumidas por votación de la mayoría del Consejo General del Instituto Nacional Electoral.

Estas actividades se realizarán bajo los lineamientos y criterios que emita el propio INE, la expectativa será entonces si con ello se logra homologar en las entidades federativas la forma de capacitar a las y los ciudadanos que conformarán el funcionariado de las mesas directivas de casilla 
y los parámetros que se tomarán en cuenta para la ubicación de casillas (cada entidad federativa cuenta con características geográficas propias) en las que la ciudadanía votará por las candidaturas de su preferencia. Este es un reto operativo de gran envergadura, los organismos locales tienen una sólida experiencia en la administración de sus procesos, resulta conveniente partir de esa experiencia para construir la nueva dinámica, pues no se puede correr el riesgo de una costosa curva de aprendizaje.

IV. Facultades especiales del Instituto Nacional Electoral

En los artículos 41, Base V, Apartado C, incisos $a, b$ y $c$ de la CPEUM; 120-125 de la Ley General de Instituciones y Procedimientos Electorales, en el titulo quinto del libro tercero "De los Organismos Electorales", se establece que el INE podrá ejercer facultades especiales, relativas a la asunción total o parcial, la atracción y la delegación; por lo que es fundamental reflexionar sobre el ejercicio de dichas facultades.

\section{Facultad de asunción}

- Es la facultad del INE de asumir ${ }^{14}$ directamente la realización de todas las actividades propias de la función electoral o de alguna actividad que corresponda a los organismos públicos locales electorales.

- Asunción total: facultad del INE de asumir directamente la realización de todas las actividades propias de la función electoral que corresponda a los organismos públicos locales electorales; la petición de asunción se podrá presentar hasta antes del inicio del proceso electoral local, y el Consejo General del INE resolverá antes de que inicie el proceso electoral local respectivo. Lo aprobará cuando menos con ocho votos de los consejeros electorales.

- Asunción parcial: facultad del INE de asumir directamente la realización de alguna actividad que corresponda a los organismos públicos locales electorales; la petición de asunción se podrá presentar en cualquier momento del proceso electoral local y se aprobará cuando menos con ocho votos de los consejeros electorales.

14 Según el Diccionario de la Real Academia Española, asumir significa hacerse cargo, responsabilizarse de algo o aceptarlo. 
- La asunción de la competencia de una elección local solo será procedente cuando se acredite fehacientemente en el procedimiento respectivo que se actualiza alguno de los siguientes supuestos:

a) Que existan diversos factores sociales que afecten la paz pública o pongan a la sociedad en grave riesgo en la entidad federativa que a decir del peticionario afectan los principios constitucionales electorales de imparcialidad, certeza, legalidad, objetividad y equidad en la contienda electoral e impiden por lo tanto, que se lleve a cabo la organización pacífica de la elección por el organismo público local competente.

b) Que no existan condiciones políticas idóneas, por injerencia o intromisión comprobable de algunos de los poderes públicos en la entidad federativa que afecten indebidamente la organización del proceso electoral por el organismo público local, al no poderse realizar todas las etapas del proceso electoral por este organismo, con imparcialidad.

- Los procedimientos de asunción se iniciarán a petición fundada y motivada ante el Instituto Nacional Electoral, de al menos cuatro de sus consejeros, o de la mayoría del Consejo General del organismo público local de una entidad federativa.

\section{Facultad de atracción}

- Facultad del INE de atraer ${ }^{15}$ a su conocimiento cualquier asunto de la competencia de los organismos públicos locales electorales, cuando su trascendencia así lo determine o para sentar un criterio de interpretación.

- La petición solo podrá formularse por al menos cuatro de los consejeros electorales del INE o la mayoría del Consejo General del organismo público local electoral. El Consejo General del INE ejercerá la facultad de atracción siempre que se apruebe cuando menos con ocho votos de los consejeros electorales.

15 Según el Diccionario de la Real Academia Española, atraer significa hacer que acudan a sí otras cosas. 


\section{Facultad de delegación}

- Facultad del INE de delegar ${ }^{16}$ a los organismos públicos locales electorales, las atribuciones siguientes:

a) La capacitación electoral.

b) La geografía electoral, así como el diseño y determinación de los distritos electorales y división del territorio en secciones electorales.

c) El padrón y la lista de electores.

d) La ubicación de las casillas y la designación de los funcionarios de sus mesas directivas.

e) Las reglas, lineamientos, criterios y formatos en materia de resultados preliminares; encuestas o sondeos de opinión; observación electoral; conteos rápidos; impresión de documentos y producción de materiales electorales.

f) La fiscalización de los ingresos y egresos de los partidos políticos y candidatos.

- Se aprobará antes del inicio del proceso electoral local correspondiente cuando menos con ocho votos de los consejeros electorales y se podrá reasumir su ejercicio directo en cualquier momento o finalizado el proceso electoral.

La naturaleza de estas atribuciones es de carácter excepcional, y debe seguirse un procedimiento específico para ejercerlas por parte del Consejo General del INE.

Sobre la facultad de atracción total de la elección, resultan oportunas las siguientes reflexiones:

Si se presenta una petición de asunción total de la elección antes de que inicie el proceso electoral - esto es un día antes o inclusive horas antes al inicio-, el Consejo General del INE deberá resolver antes de que inicie el proceso electoral. Por lo que, ¿en qué momento se sustanciará el procedimiento por parte del secretario ejecutivo del INE?

16 Según el Diccionario de la Real Academia Española, delegar significa dar a otro la jurisdicción que tiene por su dignidad u oficio, para que haga sus veces o para conferirle su representación. 
Este procedimiento incluye:

1) Registro de la petición, publicación y prevención al actor.

2) Emisión del acuerdo de apertura de procedimiento en el que se determinará la admisión de desechamiento de la petición.

3) En caso de admisión, se deberá emplazar al organismo electoral de la entidad federativa correspondiente, para que comparezca en el procedimiento.

4) Investigación y desahogo de pruebas.

En esta investigación se tomarán en cuenta además de las pruebas que obren en el procedimiento, las opiniones de todos los partidos políticos que participan en el proceso, de los poderes del estado y otros actores políticos que puedan incidir en el proceso.

5) Finalmente se resolverá por parte del Consejo General del INE.

Por tanto, tenemos un procedimiento que dista de ser sumario en virtud de las actuaciones que tendrán que llevarse a cabo para su sustanciación y que por tanto, el Consejo General del INE, contará con los elementos para resolver en un día o unas cuantas horas antes de que inicie el proceso electoral respectivo, como lo establece la norma.

Otro aspecto relevante es que la decisión que tome el Consejo General del INE podrá impugnarse ante la Sala Superior del Tribunal Electoral, lo que implica que sea un asunto sub judice (que podrá resolverse en cualquier etapa del proceso electoral), lo que trastocaría el principio de certeza. Por lo que la presentación de la petición de atracción total de la elección debe realizarse en un plazo razonable a efecto de permitir la sustanciación del procedimiento.

\section{Facultades de los organismos públicos locales electorales}

Los organismos públicos locales electorales ejercerán funciones en las siguientes materias: ${ }^{17}$

- Derechos y el acceso a las prerrogativas de los candidatos y partidos políticos.

17 Artículo 41, Base V, Apartado C, de la Constitución Política de los Estados Unidos Mexicanos. 
- Educación cívica.

- Preparación de la jornada electoral.

- Impresión de documentos y la producción de materiales electorales.

- Escrutinios y cómputos.

- Declaración de validez y el otorgamiento de constancias en las elecciones locales.

- Cómputo de la elección del titular del Poder Ejecutivo.

- Resultados preliminares, encuestas o sondeos de opinión, observación electoral, y conteos rápidos, conforme a los lineamientos expedidos por el Instituto Nacional Electoral.

- Organización, desarrollo, cómputo y declaración de resultados en los mecanismos de participación ciudadana que prevea la legislación local.

- Todas las no reservadas al Instituto Nacional Electoral.

Para transitar de manera armónica en la distribución de competencias entre el INE y los organismos públicos locales electorales será fundamental la permanente comunicación, interacción y coordinación entre ambas autoridades electorales.

En ese sentido, resulta esencial la actividad que genere al respecto la Comisión de Vinculación del Consejo General del INE ${ }^{18}$ y la Unidad Técnica de Vinculación.

\section{Conclusiones}

- Transitamos a un nuevo sistema nacional electoral en el que el INE y los organismos públicos locales electorales, deben apegarse al principio de distribución de competencias para realizar la función electoral en el país.

- La rectoría de los procesos electorales y elevar la calidad de la función electoral deben ser las metas del nuevo modelo. Para ello, será fundamental la comunicación permanente entre las autoridades administrativas electorales, en un marco de pares.

- La armonización del sistema dependerá en gran medida del trabajo legislativo que realicen los congresos de las entidades federativas y la Asamblea del Distrito Federal.

18 Acuerdo INE/CG46/2014 del Consejo General del INE. 
- Las elecciones de 2015 serán el escenario de la puesta en marcha del nuevo modelo y seguramente se definirán aspectos trascendentales por parte de la Suprema Corte de Justicia de la Nación y el Tribunal Electoral del Poder Judicial de la Federación, que darán certeza a las elecciones sucesivas.

- Queda pendiente la promulgación de la ley reglamentaria del artículo 134 de la CPEUM. Un tema que ha permanecido en el tintero desde la reforma constitucional de 2007.

\section{Fuentes consultadas}

Astudillo, César y Córdova, Lorenzo, Los árbitros de las elecciones estatales. Una radiografía de su arquitectura institucional, México, UNAM, 2010.

Constitución Política de los Estados Unidos Mexicanos.

Documento "Pacto por México".

Dictamen de las Comisiones Unidas de Puntos Constitucionales; de Gobernación; de Reforma del Estado, y de Estudios Legislativos Segunda, de la Cámara de Senadores, en relación con las iniciativas con Proyecto de Decreto por el que se reforman y adicionan diversos artículos de la Constitución Política de los Estados Unidos Mexicanos en materia política-electoral, del 2 de diciembre de 2013.

Diccionario de la Real Academia Española.

Ensayo "Es necesario convertir el Instituto Federal Electoral en autoridad nacional electoral", México, Cámara de Diputados, 2013, www.diputa dos.gob.mx/documentos/consejeros_2013/ensayo/04.pdf.

Fuente, Alejandro de la, El sistema electoral en México, http://www.le trasjuridicas.com/Volumenes/14/delafuente14.pdf.

IDEA Internacional, Justicia Electoral: El manual de IDEA Internacional, 2013.

Ley General de Instituciones y Procedimientos Electorales.

Ley General de Partidos Políticos.

Nohlen, Dieter, Los sistemas electorales en América Latina y el debate sobre la reforma electoral, UNAM, México, 1993. 